\title{
Perfil epidemiológico da sífilis gestacional: uma análise comparativa entre Minas
}

\section{Gerais e Brasil}

\author{
Epidemiological profile of gestational syphilis: a comparative analysis between Minas Gerais and \\ Brazil \\ Perfil epidemiológico de la sífilis gestacional: un análisis comparativo entre Minas Gerais y Brasil
}

Recebido: 09/12/2021 | Revisado: 17/12/2021 | Aceito: 24/12/2021 | Publicado: 04/01/2022

\author{
Eduarda Canedo Nogueira \\ ORCID: https://orcid.org/0000-0002-3654-9228 \\ Centro Universitário de Patos de Minas, Brasil \\ E-mail: eduardacanedo@hotmail.com \\ Bárbara Oliveira Vasconcelos Souto \\ ORCID: https://orcid.org/0000-0003-3399-469X \\ Centro Universitário de Patos de Minas, Brasil \\ E-mail: barbarasouto@unipam.edu.br \\ Bethânya Helena Silva de Oliveira \\ ORCID: https://orcid.org/0000-0001-7284-6046 \\ Centro Universitário de Patos de Minas, Brasil \\ E-mail: bethanyahso@unipam.edu.br \\ Bruna Alves de Matos \\ ORCID: https://orcid.org/0000-0002-3146-4663 \\ Centro Universitário de Patos de Minas, Brasil \\ E-mail: brunamatos@unipam.edu.br \\ Cecília Pereira Silva \\ ORCID: https://orcid.org/0000-0002-9412-0657 \\ Centro Universitário de Patos de Minas, Brasil \\ E-mail: ceciliaps@gmail.com \\ Emilayne Nicácio Dias Brito \\ ORCID: https://orcid.org/0000-0002-4002-8847 \\ Centro Universitário de Patos de Minas, Brasil \\ E-mail: emilaynendb@unipam.edu.br \\ Luana Damaceno Miranda \\ ORCID: https://orcid.org/0000-0003-4013-2414 \\ Centro Universitário de Patos de Minas, Brasil \\ E-mail: luanad.m@hotmail.com \\ Nicolly Skarlet Souto Oliveira \\ ORCID: https://orcid.org/0000-0003-3304-9946 \\ Centro Universitário de Patos de Minas, Brasil \\ E-mail: nicollysso@unipam.edu.br \\ Flávio Rocha Gil \\ ORCID: https://orcid.org/0000-0003-2797-6030 \\ Centro Universitário de Patos de Minas, Brasil \\ E-mail: frgil@terra.com.br \\ Valter Paz do Nascimento Júnior \\ ORCID: https://orcid.org/0000-0003-4498-2811 \\ Centro Universitário de Patos de Minas, Brasil \\ E-mail: valterpnj@unipam.edu.br
}

\section{Resumo}

Objetivo: Descrever o perfil epidemiológico de mulheres diagnosticadas com sífilis gestacional em Minas Gerais e no Brasil entre os anos de 2014 e 2018. Metodologia: Estudo epidemiológico descritivo referente aos casos de sífilis em gestante notificados no site do Departamento de Informática do SUS. As variáveis coletadas foram os dados sociodemográficos, a distribuição geográfica dos casos, os testes treponêmicos e não treponêmicos e a classificação clínica. Os dados foram tabulados e tratados de forma quantitativa e submetidos à análise descritiva. Resultados: No Brasil foram notificados 220.941 casos de sífilis em gestantes entre os anos de 2014 e 2018, com 7,35\% em Minas Gerais, apresentando alta na taxa de incidência. Em relação à faixa etária e à escolaridade, a maior frequência está em mulheres entre 20 e 39 anos, com 19,8 \% apresentando da $5^{\text {a }}$ a $8^{\text {a }}$ séries do ensino fundamental incompletas. Aumentou a realização de testes, principalmente na Região Sudeste, com Minas Gerais ocupando a terceira posição nacional, representando 5,35\% dos testes treponêmicos reativos e 7,79\% dos testes não treponêmicos reativos. A 
classificação clínica prevalente foi a sífilis primária em gestantes de 15 a 59 anos. Ocorreu um notável número de casos ignorado/branco nas variáveis analisadas, o que corresponde a uma elevada subnotificação quanto à sífilis gestacional. Conclusão: Os resultados apontam um aumento no número de casos de sífilis gestacional no Brasil e em Minas Gerais, evidenciando a necessidade do investimento na ampliação do acesso à informação em saúde para mulheres.

Palavras-chave: Sífilis; Gestantes; Epidemiologia; Notificação de doenças; Brasil.

\begin{abstract}
Objective: Describe the epidemiological profile of women diagnosed with gestational syphilis in Minas Gerais and Brazil between the years 2014 and 2018. Methodology: Descriptive epidemiological study regarding the cases of syphilis in pregnant women reported on the website of the Department of Informatics of the SUS. The variables collected were sociodemographic data, the geographical distribution of cases, treponemal and nontreponemal tests, and clinical classification. The data were tabulated and treated quantitatively and subjected to descriptive analysis. Results: In Brazil, 220,941 cases of syphilis in pregnant women were reported between the years 2014 and 2018, with $7.35 \%$ in Minas Gerais, showing a high incidence rate. Regarding age group and education, the highest frequency is in women between 20 and 39 years old, with $19.8 \%$ presenting incomplete 5th to 8th grades of elementary school. Testing increased, especially in the Southeastern Region, with Minas Gerais occupying the third national position, representing $5.35 \%$ of reactive treponemal tests and $7.79 \%$ of reactive nontreponemal tests. The prevalent clinical classification was primary syphilis in pregnant women aged 15 to 59 years. A notable number of ignored/white cases occurred in the analyzed variables, which corresponds to a high underreporting regarding gestational syphilis. Conclusion: The results point to an increase in the number of gestational syphilis cases in Brazil and Minas Gerais, evidencing the need for investment in expanding access to health information for women.
\end{abstract}

Keywords: Syphilis; Pregnant women; Epidemiology; Disease notification; Brazil.

\title{
Resumen
}

Objetivo: Describir el perfil epidemiológico de las mujeres diagnosticadas con sífilis gestacional en Minas Gerais y Brasil entre los años 2014 y 2018. Metodología: Estudio epidemiológico descriptivo sobre los casos de sífilis en gestantes notificados en el sitio web del Departamento de Informática del SUS. Las variables recogidas fueron los datos sociodemográficos, la distribución geográfica de los casos, las pruebas treponémicas y no treponémicas y la clasificación clínica. Los datos se tabularon y trataron cuantitativamente y se sometieron a un análisis descriptivo. Resultados: En Brasil se notificaron 220.941 casos de sífilis en mujeres embarazadas entre los años 2014 y 2018 , con un 7,35\% en Minas Gerais, mostrando una alta tasa de incidencia. En cuanto al grupo de edad y a la educación, la mayor frecuencia se da en las mujeres de entre 20 y 39 años, con un 19,8\% que presenta los cursos de $5^{\circ}$ a $8^{\circ}$ de primaria incompletos. El rendimiento de las pruebas aumentó, especialmente en la Región Sudeste, con Minas Gerais ocupando la tercera posición nacional, representando el 5,35\% de las pruebas treponémicas reactivas y el 7,79\% de las pruebas no treponémicas reactivas. La clasificación clínica prevalente fue la de sífilis primaria en mujeres embarazadas de 15 a 59 años. Hubo un número notable de casos ignorados/blanco en las variedades analizadas, lo que corresponde a una elevada subnotificación respecto a la sífilis gestacional. Conclusión: Los resultados apuntan a un aumento del número de casos de sífilis gestacional en Brasil y en Minas Gerais, evidenciando la necesidad de invertir en la ampliación del acceso a la información en salud para las mujeres.

Palabras clave: Sífilis; Mujeres embarazadas; Epidemiología; Notificación de enfermedades; Brasil.

\section{Introdução}

A sífilis é um grave problema de saúde pública, atingindo aproximadamente 12 milhões de pessoas no mundo por ano.

No Brasil, tem-se observado um aumento na taxa de detecção de sífilis em gestantes a partir de 2006, com o registro de 7,4 casos/1000 nascidos vivos em 2013 (Tiago, et al., 2017).

No Brasil, a sífilis em gestantes é doença de notificação compulsória desde 2005 (Portaria nº 33/2005), devendo ser notificada semanalmente aos órgãos responsáveis (Guimarães, et al., 2018). As informações sobre os casos de sífilis na gravidez devem ser inseridas no Sistema de Informação de Agravos de Notificação (SINAN), uma vez que o monitoramento de doenças por meio desse sistema é de suma importância para o acompanhamento adequado das mesmas, visto que fornece subsídios para o planejamento de estratégias, dentre as quais se pode citar as políticas públicas (Silva, et al., 2020).

A sífilis é uma infeção de caráter sistêmico e evolução crônica, ademais está sujeita a períodos de latência e surtos de agudização. O agente etiológico responsável pela doença é o Treponema pallidum, uma bactéria gram-negativa do grupo das 
espiroquetas, que pode ser transmitida de forma sexual ou vertical e causar, respectivamente, a forma adquirida ou congênita da doença (Guimarães, et al., 2018).

A sífilis adquirida pode ser dividida em duas categorias, recente caso o tempo de evolução da doença for inferior a um ano (primária, secundária e latente recente) e tardia (latente tardia e terciária) caso o tempo de evolução for maior que um ano (Ministério da Saúde, 2020).

Geralmente, a infecção do feto ocorre entre a $16^{\mathrm{a}}$ e a $28^{\mathrm{a}}$ semanas de gestação, sendo que a taxa de transmissão materno-fetal do Treponema palidum em mulheres que não realizaram o tratamento varia de 70 a $100 \%$, considerando-se a fase primária e secundária da doença. Os desfechos desfavoráveis relacionados com a sífilis durante a gestação em mulheres que não recebem tratamento são: aborto espontâneo, natimorto ou morte perinatal em cerca de $40 \%$ das crianças infectadas (Silva, et al., 2020).

Diante do reconhecimento da sífilis na gestação como problema de saúde pública, é essencial o estudo da realidade dessa patologia em todo o território nacional a fim de que medidas preventivas e de controle de casos possam ser implementadas. Desse modo, este artigo tem como objetivo traçar o perfil epidemiológico das notificações compulsórias de sífilis em gestantes, registradas em Minas Gerais do período de 2014 a 2018, bem como comparar com os dados do Brasil. Essa comparação tem o propósito de obter, além de dados nacionais, uma visão de dados regionais.

\section{Metodologia}

Trata-se de um estudo epidemiológico descritivo, com abordagem quantitativa. O caráter descritivo versa como a incidência e a prevalência de uma patologia ou condição relacionada à saúde. As pesquisas descritivas têm como finalidade principal a descrição das características de determinada população ou fenômeno, bem como o estabelecimento de associações entre variáveis. Desse modo, varia de acordo com determinadas características, como sexo, idade, escolaridade e renda, entre outras. A abordagem quantitativa coleta informações de natureza numérica e que serão analisadas usando métodos estatísticos, com posterior elaboração de tabelas (Gil, 2002).

Para a coleta de dados foram utilizadas as informações epidemiológicas referentes aos casos de sífilis em gestante notificados no período de 2014 a 2018, disponíveis no site do Departamento de Informática do Sistema Único de Saúde (DATASUS), especificamente a ferramenta Informação em Saúde (TABNET), onde constam dados do Sistema de Informação de Agravos de Notificação (SINAN). As variáveis coletadas foram os dados sociodemográficos (escolaridade e faixa etária), a distribuição geográfica dos casos com destaque para o Brasil e Minas Gerais, os testes treponêmicos e não treponêmicos e a classificação clínica. O levantamento de dados ocorreu no período de setembro a outubro de 2021.

Os dados foram tabulados e tratados de forma quantitativa, organizados em tabelas e gráficos através do software Statistical Package for the Social Sciences (SPSS) versão 20.0 e Microsoft Office Excel e submetidos à análise descritiva, apresentados através de distribuição de frequência simples e relativa.

Os dados estudados são de domínio público, colhidos a partir do Ministério da Saúde e, portanto, não carecem de avaliação pelo Comitê de Ética em Pesquisa (CEP).

\section{Resultados}

No Brasil, entre os anos de 2014 e 2018, foram notificados 220.941 casos de sífilis em gestantes. Essa enfermidade tem apresentado um crescimento exponencial nos últimos anos, sendo Minas Gerais o terceiro estado com maior aumento no número de casos, equivalendo-se de 7,35 \% do valor nacional. Ao analisar os dados da Figura 1, fica evidente o aumento das notificações de sífilis em gestantes. 
Considerando a população de Minas Gerais segundo o último censo (2010) realizado pelo Instituto Brasileiro de Geografia e Estatística (IBGE, 2021), 19.597.330 pessoas, com relação à taxa de incidência de sífilis gestacional, o estado avaliado teve um aumento de $675 \%$ em cinco anos.

Figura 1 - Distribuição de casos confirmados de sífilis no Brasil e em Minas Gerais segundo o ano de diagnóstico.

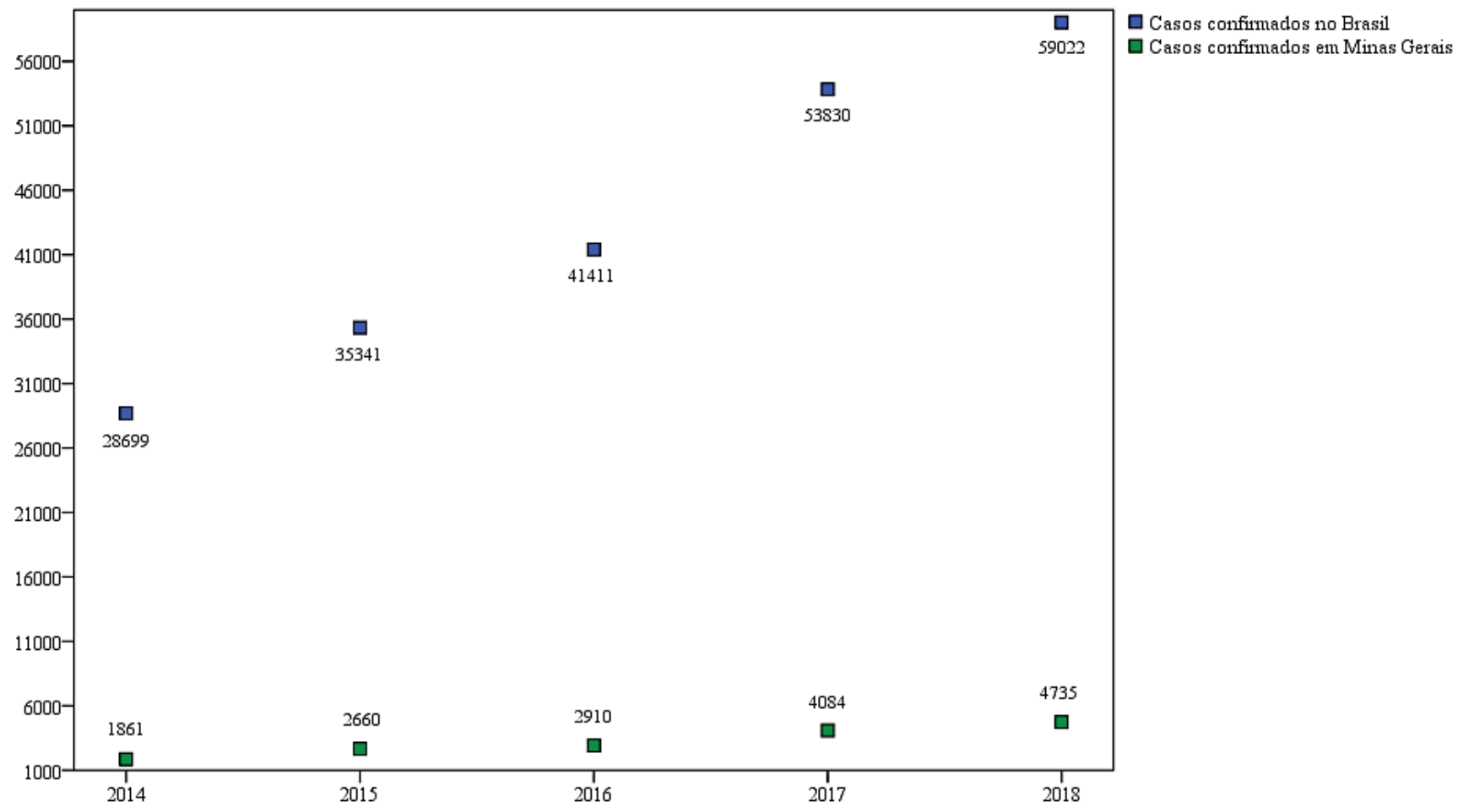

Fonte: Ministério da Saúde/SVS - Sistema de Informação de Agravos de Notificação - Sinan Net (2021).

No que diz respeito à faixa etária, a Tabela 1 ilustra a prevalência de mulheres com sífilis gestacional no Brasil entre os anos de 2014 e 2018, sendo maior dos 20 aos 39 anos, com 70,8\% no total, concentrando a porcentagem próxima de 46,2\% na Região Sudeste e 16\% no estado de Minas Gerais. Ademais, no que se refere ao período dos 15 aos 19 anos, ele representa $25,8 \%$ das notificações totais no país, sendo a Região Sudeste detentora de aproximadamente 45,4\% e Minas Gerais 16,5\% desses dados.

Por outro lado, as pré-adolescentes de 10 a 14 anos revelaram taxa nacional por volta de 1,3\%, constando na Região Sudeste e no estado de Minas Gerais aproximadamente 40,9\% e 15,4\%, respectivamente. Finalmente, as que pertencem ao grupo de 40 a 59 anos exibem taxas de quase $2 \%$ em todo território brasileiro, consistindo $44,4 \%$ no Sudeste e 9,8\% em Minas Gerais.

No que tange à escolaridade (Tabela 1), a prevalência de mulheres com sífilis gestacional no Brasil entre os anos de 2014 e 2018 é maior naquelas que possuem da $5^{\mathrm{a}}$ a $8^{\mathrm{a}}$ série incompleta do ensino fundamental, apresentando uma porcentagem de 19,8\% do valor total. Nessa mesma perspectiva, o estado de Minas Gerais, bem como a Região Sudeste também apresentaram destaque para essa mesma faixa de escolaridade, constando $16,5 \%$ e $17,1 \%$ respectivamente.

Observa-se também que, em última instância, se encontra o índice de analfabetismo, compreendendo, desse modo, a baixa prevalência de mulheres sem nenhum conhecimento de leitura e escrita com os atributos da pesquisa. Entretanto, essa análise poderia abarcar um teor mais elevado no conteúdo dos demais dados citados, visto que os casos ignorados ou em 
branco em relação à escolaridade das gestantes com sífilis tanto no Brasil, quanto em Minas Gerais e na Região Sudeste atingiram, de maneira respectiva, $27,9 \%, 38,6 \%$ e $29,6 \%$ do valor total das categorias.

Tabela 1 - Casos notificados de sífilis gestacional por faixa etária e escolaridade em Minas Gerais, na Região Sudeste e no Brasil, entre 2014 e 2018.

\begin{tabular}{|c|c|c|c|c|}
\hline & Variável & Minas Gerais & Sudeste & Brasil \\
\hline \multirow{4}{*}{ Faixa Etária (anos) } & $10-14$ & 182 & 1.178 & 2.875 \\
\hline & $15-19$ & 4.302 & 25.975 & 57.089 \\
\hline & $20-39$ & 11.651 & 72.386 & 156.516 \\
\hline & $40-59$ & 290 & 1.923 & 4.326 \\
\hline \multirow{10}{*}{ Escolaridade } & Analfabeto & 50 & 862 & 1.822 \\
\hline & $1^{\mathrm{a}} \mathrm{a} 4^{\mathrm{a}}$ série incompleta do $\mathrm{EF}$ & 465 & 3.890 & 10.797 \\
\hline & $4^{\mathrm{a}}$ série completa do $\mathrm{EF}$ & 422 & 3.221 & 7.911 \\
\hline & $5^{\mathrm{a}}$ a $8^{\mathrm{a}}$ série incompleta do $\mathrm{EF}$ & 2.716 & 17.371 & 43.765 \\
\hline & Ensino fundamental completo & 1.580 & 10.001 & 21.405 \\
\hline & Ensino médio incompleto & 2.109 & 15.245 & 31.464 \\
\hline & Ensino médio completo & 2.447 & 18.615 & 37.189 \\
\hline & Educação superior incompleta & 162 & 1.221 & 2.820 \\
\hline & Educação superior completa & 131 & 926 & 2.100 \\
\hline & Não se aplica/ Ignorado/Branco & 6.344 & 30.110 & 61.668 \\
\hline \multicolumn{2}{|r|}{ Total } & 16.426 & 101.462 & 220.941 \\
\hline
\end{tabular}

Fonte: Ministério da Saúde/SVS - Sistema de Informação de Agravos de Notificação - Sinan Net (2021).

A Tabela 2 evidencia o aumento na realização de testes de 2014 a 2018 para detectar a sífilis em gestantes no estado de Minas Gerais. Comparando a quantidade de testes treponêmicos realizados em 2014 (867) com os 3.116 testes de 2018, houve um aumento de $359,40 \%$. Em relação ao teste não treponêmico, o aumento foi menor que no teste treponêmico, correspondendo a $233,40 \%$. Além disso, observa-se que a quantidade de ambos os testes sofreu um acréscimo maior/igual a 800 em 2017, reduzindo em 2018, com o teste não treponêmico apresentando cerca de 60\% da redução entre os anos citados.

Tabela 2 - Casos notificados de sífilis em gestantes por testes treponêmicos e não treponêmicos em Minas Gerais segundo o ano de diagnóstico.

\begin{tabular}{lccccc}
\hline \multicolumn{1}{c}{ Variável } & $\mathbf{2 0 1 4}$ & $\mathbf{2 0 1 5}$ & $\mathbf{2 0 1 6}$ & $\mathbf{2 0 1 7}$ & $\mathbf{2 0 1 8}$ \\
\hline Teste treponêmico & & & & & \\
Reativo & 778 & 1.193 & 1.458 & 2.168 & 2.882 \\
Não Reativo & 89 & 133 & 109 & 199 & 234 \\
& & & & & \\
Teste não treponêmico & & & & & 3.855 \\
Reativo & 1.731 & 2.472 & 2.622 & 3.484 & 274 \\
Não Reativo & 38 & 48 & 100 & 246 & \\
\hline
\end{tabular}

Fonte: Ministério da Saúde/SVS - Sistema de Informação de Agravos de Notificação - Sinan Net (2021). 
Ao avaliar a realização de testes para o diagnóstico da sífilis gestacional pela Tabela 3, a Região Sudeste apresentou mais de $45 \%$ da população dos casos analisados, sendo essa prevalência distribuída em 20,47\%, 15,02\%, 7,43\% e 3,04\% respectivamente para São Paulo, Rio de Janeiro, Minas Gerais e Espírito Santo.

Tabela 3 - Casos notificados de sífilis em gestantes por testes treponêmicos e não treponêmicos no Brasil segundo a Unidade Federativa e a Região de notificação entre 2014 e 2018.

\begin{tabular}{|c|c|c|c|c|c|}
\hline Variável & Reativo & Não reativo & Não realizado & Ignorado/Branco & Total N(\%) \\
\hline \multicolumn{6}{|c|}{ Teste do tipo treponêmico } \\
\hline São Paulo & 38.820 & 966 & 3.728 & 1.729 & $45.243(20,47)$ \\
\hline Rio de Janeiro & 21.643 & 989 & 6.599 & 3.963 & $33.194(15,02)$ \\
\hline Minas Gerais & 8.566 & 768 & 5.188 & 1.904 & $16.426(7,43)$ \\
\hline Espírito Santo & 3.888 & 229 & 2.011 & 590 & $6.718(3,04)$ \\
\hline Região Nordeste & 28.644 & 1.404 & 10.608 & 4.303 & $44.959(20,34)$ \\
\hline Região Sul & 26.256 & 1.068 & 5.256 & 2.367 & $34.947(15,81)$ \\
\hline Região Norte & 11.998 & 826 & 7.060 & 2.156 & $22.040(9,97)$ \\
\hline Região Centro-Oeste & 13.379 & 498 & 2.241 & 1.296 & $17.414(7,88)$ \\
\hline \multicolumn{6}{|c|}{ Teste do tipo não treponêmico } \\
\hline São Paulo & 40.294 & 2.456 & 1.453 & 1.040 & $45.243(20,47)$ \\
\hline Rio de Janeiro & 19.902 & 983 & 8.720 & 3.589 & $33.194(15,02)$ \\
\hline Minas Gerais & 14.329 & 707 & 984 & 406 & $16.426(7,43)$ \\
\hline Espírito Santo & 5.273 & 203 & 956 & 286 & $6.718(3,04)$ \\
\hline Região Nordeste & 34.130 & 1.700 & 5.665 & 3.464 & $44.959(20,34)$ \\
\hline Região Sul & 29.633 & 1.640 & 2.490 & 1.184 & $34.947(15,81)$ \\
\hline Região Norte & 17.544 & 653 & 2.435 & 1.408 & $22.040(9,97)$ \\
\hline Região Centro-Oeste & 12.834 & 1.471 & 1.872 & 1.237 & $17.414(7,88)$ \\
\hline
\end{tabular}

Fonte: Ministério da Saúde/SVS - Sistema de Informação de Agravos de Notificação - Sinan Net (2021).

Considerando os casos em que o teste treponêmico foi realizado (159.942), em Minas Gerais o teste foi reativo em 8.566 (5,35\%) e não reativo em 768 (0,48\%), com o estado avaliado correspondendo a 5,83\% dos casos do Brasil. Porém ainda há uma elevada porcentagem de casos com resultado ignorado/branco, 1904 (10,40\%), em relação ao total de notificações.

Mediante a realização do teste não treponêmico, constatou-se em Minas Gerais 8,18\% dos 183.752 casos notificados, sendo 14.329 (7,79\%) reativos e 707 (0,38\%) não reativos, com 406 (3,21\%) ignorados/brancos. Este não foi realizado em 984 casos, já o teste treponêmico não foi realizado em 5.188 gestantes.

Diante dessa avaliação (Tabela 3), foi perceptível o aumento de 67,27\% nos casos reativos quando consideramos o teste não treponêmico em relação ao treponêmico, bem como ocorreu uma redução de 7,94\% em casos não reativos.

Tendo em vista os dados expostos na Tabela 4, é possível analisar conforme a classificação clínica da patologia, em relação à faixa etária, uma maior relevância nas variáveis ignorado/branco e primária, de modo que são mais expressas entre os 20 e 39 anos (71,22\%), moderadamente entre 15 e 19 anos (26,96\%) e de maneira mais discreta entre 40 e 59 anos $(1,81 \%)$. Na 
forma secundária, é possível notar um aumento significativo de notificações entre os 20 e 39 anos (72,51\%), sendo pouco expressa entre 15 e 19 anos (25,81\%), e minimamente entre os 40 e 59 anos (1,67\%).

Em relação às demais, a forma terciária é a menos evidente, de modo que ela está mais presente entre os 20 e 39 anos (72,59\%), de maneira mediana entre 15 e 19 anos (25,95\%) e reduzida entre 40 e 59 anos (1,44\%). Quanto à classificação latente, é visto que se manifesta em grande parte dos indivíduos com a patologia, uma vez que é facilmente identificada entre 20 e $39 \operatorname{anos}(73,07 \%)$, moderadamente entre 15 e 19 anos $(25,04 \%)$ e pouco identificada entre 40 e 59 anos $(1,88 \%)$.

Tabela 4 - Casos notificados de sífilis em gestantes por faixa etária segundo a classificação clínica entre 2014 e 2018 em Minas Gerais.

\begin{tabular}{ccccc}
\hline Classificação Clínica & $\mathbf{1 5}-\mathbf{1 9}$ & $\mathbf{2 0 ~ - ~ 3 9}$ & $\mathbf{4 0 ~ - ~ 5 9}$ & Total \\
\hline Primária & 1631 & 3914 & 86 & 5631 \\
Secundária & 309 & 868 & 20 & 1197 \\
Terciária & 251 & 702 & 14 & 967 \\
Latente & 718 & 2095 & 54 & 2867 \\
Ignorado/Branco & 1392 & 4072 & 117 & 5581 \\
\hline Total & 4301 & 11651 & 291 & 16243 \\
\hline
\end{tabular}

Fonte: Ministério da Saúde/SVS - Sistema de Informação de Agravos de Notificação - Sinan Net (2021).

Ao comparar a classificação clínica com as idades, percebe-se a prevalência da classificação primária entre 20 e 39 anos, com uma diferença de 27,56\% em relação à classificação terciária, sendo esta a menos comum. Considerando a sífilis primária relevante, é notável que essa infecção apresenta uma diferença de $67,98 \%$ ao comparar os casos de pacientes entre 20 e 39 anos com aqueles que têm entre 40 e 59 anos, sendo estes menos prevalentes em todas as classificações avaliadas. Com isso, é possível analisar a relevância da classificação da sífilis, pois seus diferentes sintomas terão diferentes condutas para cada faixa etária.

\section{Discussão}

O número de casos de sífilis gestacional no Brasil aumentou entre os anos de 2014 a 2018, podendo ser atribuído a fatores como, a intensificação da vigilância pelas Secretarias de Saúde, a melhora nos bancos de dados, o aumento da cobertura de testagem com a ampliação do uso de testes rápidos, a redução do uso de preservativo e o desabastecimento mundial de penicilina (Andrade, et al., 2019). Em consonância com os dados do presente estudo analisados a partir do Sinan Net, Amorim et al. (2021) destacou o crescimento estatisticamente significativo nas taxas de incidência de sífilis em gestantes de Minas Gerais através do cálculo da variação percentual média anual (APC), o que resultou em 36,7\%. A partir desses dados, evidencia-se tratar de um problema de saúde pública a ser enfrentado no estado.

No período de 2008 a 2014, o maior grupo de casos de mulheres notificadas está entre 20 e 29 anos (Souza \& Benito, 2016). Ainda sobre esta faixa, Minas Gerais também constatou maior prevalência, com 52,9\% do total em estudo feito de 2002 a 2019 (Leão, et al., 2021). O fato de o auge da fase reprodutiva estar nesse período justifica um maior número de gestações nessa faixa etária.

Em relação ao intervalo dos 20 aos 39 anos, até 2014 foram 66.799 notificações de sífilis gestacional (Souza \& Benito, 2016). No período de 2014 a 2018 houve um crescimento, chegando a valores de 156.516, mais que o dobro de antes. Assim como nas outras faixas, a Região Sudeste concentra 46,2\% desses achados. Tal quadro demonstra a alta prevalência 
dessa doença entre as mulheres que ainda estão em idade reprodutiva, exprimindo que ainda é preciso maior qualidade e alcance da informatização quanto a práticas preventivas e sobre os riscos dessa doença para o binômio.

Além disso, um aspecto que chama a atenção é o número de gestantes adolescentes. Na Tabela 1, percebe-se que, de 2014 a 2018, a faixa de 15 a 19 anos atingiu o número de 57.089 casos, com superioridade da Região Sudeste contando com quase $45,4 \%$ dos casos e Minas Gerais correspondendo a 16,5\% dos casos dessa região de 7,5\% das notificações do total dessa faixa. Ademais, está exposto que faixas etárias ainda mais jovens apresentam número significativo de casos, sendo 2875 casos em pré-adolescentes (10 a 14 anos), com a Região Sudeste novamente como líder possuindo aproximadamente 40,9\% dos casos, tendo Minas Gerais por volta de $15,4 \%$ desse valor.

Nesse aspecto, tais dados revelam que o comportamento sexual de adolescentes se apresenta como um empecilho no panorama da saúde pública. Isso porque a exposição exacerbada marcada por atividade sexual precoce, uso irregular de preservativos e múltiplos parceiros reflete falhas educacionais em saúde voltadas para este grupo, principalmente no que tange a gestação (Caldana, et al., 2021). Desse modo, as pesquisas são preocupantes, uma vez que existem consequências psicossociais e econômicas nos contextos de vida familiar e social dessas jovens.

Por outro lado, no período de 2014 a 2018, o número de grávidas portadoras de sífilis que possuem de 40 a 59 anos foi de 4326, sendo que, em 2014, foram encontrados 2.324 casos em mulheres com mais de 40 anos (Souza \& Benito, 2016). A Região Sudeste, ainda majoritária, obteve uma porcentagem próxima de 44,4\%, sendo Minas Gerais representante de 9,8\% dessa amostra. Apesar da elevação, o fator pelo qual o número é mais baixo que nas faixas de 15 a 39 pode ser baseado no comportamento sexual menos ativo.

Em relação ao nível de escolaridade das mulheres que apresentaram sífilis gestacional, a maior prevalência encontrada neste estudo foi entre aquelas que não completaram da $5^{\mathrm{a}}$ a $8^{\mathrm{a}}$ séries. De maneira equiparável, a pesquisa realizada entre os anos de 2009 a 2019 de Leão et al. (2020) demonstra porcentagens semelhantes desses casos com o mesmo nível de escolaridade em Minas Gerais, sendo o maior deles 20,9\% no primeiro ano analisado. Ademais, Barbosa e colaboradores (2017) ressaltam novamente a faixa da $5^{\mathrm{a}}$ a $8^{\mathrm{a}}$ série incompleta do ensino fundamental predominante em pessoas diagnosticadas com sífilis gestacional, com uma porcentagem de 27,5\%, dessa vez no estado do Piauí, dentre os anos de 2010 a 2013. Embora esses estudos citados façam referência a dados de anos anteriores aos do presente artigo, ainda no Brasil, mesmo recentemente a realidade se mantem similar.

Sob outra perspectiva, o número de casos notificados que foram ignorados ou deixados em branco, equivalente a 38,6\% em Minas Gerais e 27,9\% no Brasil, ultrapassa as demais categorias analisadas pelo presente estudo. Essa condição impede que a análise dos dados se torne ainda mais fidedigna, visto que a amostragem se fez menos representativa. Em paralelo, segundo Mesquita et al. (2012) em seu estudo realizado entre os anos de 2006 a 2010, 36,4\% dos casos mencionados foram ignorados. Aliado a isso, Cavalcante e colaboradores (2021) em sua pesquisa entre os anos de 2016 a 2019, também citou a respeito da faixa de escolaridade ignorada, apresentando um percentual de aproximadamente $30 \%$. Dessa forma, é importante salientar a necessidade do preenchimento das fichas de notificação pelos profissionais de saúde.

Ao analisar a prevalência dos casos de mulheres que apresentam sífilis gestacional e correlacionar com a escolaridade dessas, é possível perceber que o perfil epidemiológico dessa população está relacionado a uma baixa escolaridade. A falta de acesso à informação em concomitância a um menor período de estudos indica que essas mulheres provavelmente não possuíam conhecimento acerca da patologia, dos meios de prevenção e da forma de tratamento. Portanto, pode-se constatar que a baixa escolaridade é um agravante em relação aos riscos à saúde, principalmente no que se refere a doenças sexualmente transmissíveis (Conceição, et al., 2019). 
O diagnóstico da sífilis é basicamente sorológico, devendo ser realizado na primeira consulta de pré-natal no primeiro trimestre de gestação e repetido no início do terceiro trimestre, para que ocorra a identificação precoce das gestantes portadoras de sífilis e o seu pronto tratamento, como medidas na prevenção da transmissão vertical. Sendo assim, a partir do primeiro teste positivo (reagente) da gestante, o tratamento deve ser iniciado, sem a necessidade de aguardar o resultado do segundo teste em prevenção da evolução da sífilis congênita (Padovani, et al., 2018; Sousa, 2021).

O Ministério da Saúde preconiza que o diagnóstico de sífilis ocorra mediante o uso dos testes treponêmicos, podendose citar o fluorescent treponemal antibody absorption test (FTA-abs), T. pallidum haemagglutination assay (TPHA), enzymelinked immunosorbent assay (ELISA), micro-hemagglutination assay for antibodies to T. pallidum (MHA-TP), teste rápido e ensaio imunológico com revelação eletroquimioluminescente (EQL), em que os anticorpos específicos podem permanecer detectáveis indefinidamente. Já alguns testes não treponêmicos são veneral disease research laboratory (VDRL), rapid plasma reagin (RPR) e toluidine red unheated serum test (TRUST), sendo estes utilizados na investigação de sífilis ativa e no segmento mensal após o tratamento das gestantes (Gaspar, et al., 2021; Moroskoski, et al., 2018). A realização dos testes citados tem aumentado expressivamente entre os anos de 2014 e de 2018 no estado de Minas Gerais, com destaque para os testes treponêmicos, os quais são testes confirmatórios e menos predispostos a apresentar resultados falsos.

Os testes treponêmicos e não treponêmicos prevaleceram na Região Sudeste, com destaque para Minas Gerais ocupando a terceira posição entre os estados que mais notificaram a sífilis gestacional. Ao comparar com o estado que apresentou o maior número de casos, que foi o estado de São Paulo, observa-se uma diferença de 28.817 (13,04\%). Em relação aos testes reativos da Região Sudeste, Minas Gerais representa 11,74\% dos testes treponêmicos e 17,95\% dos testes não treponêmicos. Esse aumento nas notificações da região pode estar relacionado à implementação de planos e estratégias desenvolvidos pelo Sistema Único de Saúde (SUS), como a Rede Cegonha e a implantação dos testes rápidos para a triagem da sífilis na atenção básica (Maschio-Lima, et al., 2019).

As demais regiões do Brasil possuem menos casos reativos, a soma de casos reativos para ambos os testes das regiões Nordeste e Sul é menor que os casos contabilizados apenas no Sudeste. Avaliando esses dados, é importante considerar o grande contingente populacional da Região Sudeste e a dificuldade de acesso aos testes em regiões com desfavorável localização, como populações ribeirinhas ou rurais. No entanto, existe um aumento crescente de casos no Brasil, o que resulta em aumento em todas as regiões, sendo positivo observar que as gestantes estão realizando os testes de rastreamento para sífilis, porém, ainda faltam instruções adequadas às populações quanto às infecções sexualmente transmissíveis (ISTs), para assim amenizar o percentual de casos reativos no país.

Diante dessa avaliação, foi perceptível o aumento em mais de $60 \%$ nos casos reativos do teste não treponêmico, o que vai de encontro com o observado por Andrade et al. (2019), no trabalho em que o mesmo teste foi reagente em $95 \%$ dos casos em uma cidade no interior de Minas Gerais. Analisando a prevalência do diagnóstico através de teste não treponêmico, é importante salientar a maior possibilidade de resultados falso-positivos para essa modalidade na gravidez, sendo recomendada a confirmação por meio de testes treponêmicos, os quais são mais específicos (Andrade, et al., 2019; Padovani, et al., 2018). Entretanto não se deve esperar o resultado de testes treponêmicos para iniciar o tratamento, uma vez que o agravo seja descartado, a administração da medicação não representa risco efetivo em comparação às possibilidades que podem ocorrer frente ao não tratamento no tempo adequado (Ministério da Saúde, 2020).

Desse modo, apesar do teste não treponêmico suplantar em questão de reatividade, deve-se considerar o aumento na realização do teste treponêmico nos anos analisados. Assim, é possível inferir que houve uma introdução deste na triagem laboratorial, correlacionando com o aumento de notificações de sífilis nos últimos anos. 
A partir da análise da elevada porcentagem de resultados ignorado/branco e não realizado, 16,83\% por teste não treponêmico e $27,60 \%$ por teste treponêmico, é importante, durante o pré-natal, o incentivo das gestantes à realização dos testes para a identificação precoce daquelas que adquiriram sífilis, viabilizando o tratamento em tempo oportuno. Pois quando essa enfermidade é tratada inadequadamente ou não é tratada, as consequências podem ser infecção do concepto, abortamentos, prematuridade e natimortalidade (Moroskoski, et al., 2018).

A classificação clínica da sífilis pode ser feita em estágios com base nos achados clínicos, no tratamento e no monitoramento, sendo então dividida em: primária, secundária, latente (recente e tardia) e terciária. Diante disso, os dados analisados evidenciaram que as gestantes na faixa etária de 20 a 39 anos apresentaram o maior número de casos de infecção por sífilis, mais especificamente, com a classificação primária. Logo, essa categoria apresenta o tempo de incubação variando entre 10 e 90 dias, sendo manifestada por lesão primária acompanhada de linfadenopatia regional, com duração de 03 a 08 semanas. Durante esse período de incubação, não há marcadores sorológicos da infecção, com a presença de anticorpos na corrente sanguínea ocorrendo cerca de 07 a 10 dias após o surgimento do cancro duro (Macêdo, et al., 2019; Ministério da Saúde, 2020). Assim, a sífilis é inicialmente detectada por teste treponêmico, o qual tem se elevado em Minas Gerais, inferindo-se que houve um aumento também no diagnóstico precoce da infecção em gestantes.

A princípio, o indivíduo apresenta o cancro duro como uma única úlcera rica em treponemas, indolor, com borda bem definida e regular, base endurecida e fundo limpo, que ocorre no local de entrada da bactéria. Na sífilis secundária haverá a presença de uma erupção macular eritematosa pouco visível, principalmente no tronco e na raiz dos membros, essas lesões progridem para lesões mais evidentes, papulosas eritematoacastanhadas, que podem atingir todo tegumento, sendo frequentes nos genitais. Em seguida, podem ser identificadas nas dobras mucosas, especialmente na área anogenital, os condilomas planos. Além disso, são comuns sintomas inespecíficos como febre baixa, mal-estar, cefaleia e adinamia. A sífilis terciária pode surgir até 40 anos após o início da infecção, provocando destruição tecidual e formação de gomas sifilíticas, nesse estágio clínico é comum o acometimento do sistema nervoso e do sistema cardiovascular (Ministério da Saúde, 2020).

Nesse aspecto, um dos maiores empecilhos enfrentados é a dificuldade em mensurar o tempo de contágio, devendo o tratamento ser ampliado a fim de evitar equívocos e riscos desnecessários. A benzilpenicilina benzatina é a única droga com eficácia documentada para o tratamento da sífilis gestacional, seu esquema terapêtico varia conforme o estadiamento da doença, sendo oferecida dose única para sífilis recente e 03 doses para a sífilis tardia (Ministério da Saúde, 2020).

De acordo com o estudo de Gomes et al., (2020), a faixa etária de mães entre 20 e 34 anos também se mostra evidente para a sífilis em gestantes, questão associada à baixa escolaridade e ao não tratamento dos parceiros sexuais. Desse modo, é interessante evidenciar que o intervalo entre essas idades se mostra coincidente ao estudo presente, logo, é possível dizer que é uma população que se deve tomar as devidas profilaxias por se mostrar com maior incidência. Após identificar essas situações de risco, fica evidente a importância do pré-natal no acompanhamento da gestante e de sua parceria sexual na atenção primária em saúde.

Apesar dos alarmantes números de casos notificados de sífilis gestacional, esses índices podem ser ainda maiores, visto que muitos profissionais desconhecem o instrumento de notificação, configurando em subnotificações. Sendo assim, impossibilita-se a implementação de estratégias de controle da patologia (Santana, 2019). Desse modo, é perceptível que mesmo o estado de Minas Gerais não liderando sobre os outros da Região Sudeste e do Brasil, não é viável desviar a atenção às notificações prevalentes e incidentes que persistem na visualização dos dados, algo que não oferece tranquilidade, mas indícios de necessidades na melhoria na conscientização referente a essa IST e ao período gravídico. 


\section{Conclusão}

Os produtos identificados através deste trabalho possibilitaram não apenas caracterizar a sífilis gestacional, como também identificar os aspectos epidemiológicos das notificações da doença em Minas Gerais em comparação com o Brasil. Nesse tocante, o aumento do número de casos foi mais expressivo entre os anos de 2014 e 2018, abrangendo mulheres de 20 a 39 anos de baixa escolaridade, sendo possível salientar o aumento preocupante de sífilis gestacional em adolescentes (15 a 19 anos) em todo o Brasil. Essa crescente de casos tem como possíveis fatores a intensificação da vigilância pelas Secretarias de Saúde, a melhora nos bancos de dados e o aumento da cobertura de testagem com a ampliação do uso de testes rápidos.

Em relação ao diagnóstico, essa investigação evidencia Minas Gerais como um dos estados com maior aumento da porcentagem de testagem, destacando-se o uso de testes treponêmicos e o predomínio do diagnóstico por testes não treponêmicos, prevalecendo também a classificação clínica como sífilis primária. O presente estudo aponta ainda o grande número de notificações ignoradas ou deixadas em branco, dificultando a criação de estratégias para a contenção da enfermidade. Conclui-se a relevância de investir na ampliação do acesso da informação em saúde para mulheres, visando também instruir sobre o crédito da notificação compulsória da doença em questão, bem como sua importante testagem. Assim, buscando amenizar não apenas a sífilis gestacional, tal como a transmissão que pode ocasionar a sífilis congênita.

Portanto, o controle da sífilis gestacional ainda configura um desafio no Brasil, assim, recomenda-se aos trabalhos futuros a exploração aprofundada, bem como, estudos a longo prazo sobre as características dos demais estados brasileiros em uma comparação daqueles com maior incidência de casos de sífilis gestacional com os estados que apresentam a menor incidência, na tentativa de delimitações de causas para o aumento. A partir da melhor compreensão do perfil dessas populações, os meios de prevenção e as políticas públicas podem se adequar aos mais acometidos por essa IST.

\section{Referências}

Amorim, E. K. R., Matozinhos, F. P., Araújo, L. A., \& Silva, T. P. R. da. (2021). Tendência dos casos de sífilis gestacional e congênita em Minas Gerais, 2009-2019: um estudo ecológico. Epidemiologia e Serviços de Saúde, 30(4), e2021128. https://doi.org/10.1590/S1679-49742021000400006

Andrade, H. S., Rezende, N. F. G., Garcia, M. N., \& Guimarães, E. A. de A. (2019). Caracterização epidemiológica dos casos de sífilis em mulheres. Ciência \& Saúde, 12(1), 32124. https://doi.org/10.15448/1983-652x.2019.1.32124

Barbosa, D. R. M., Almeida, M. G. de, Silva, A. O., Araújo, A. A., \& Santos, A. G. dos. (2017). Perfil epidemiológico dos casos de sífilis gestacional. Revista de Enfermagem UFPE on Line, 11(5), 1867-1874. https://doi.org/10.5205/1981-8963-V11I5A23335P1867-1874-2017

Caldana, N., Dias, C. C., Wiss, C. R., Cruz, M. de C., \& Castro, V. L. P. de. (2021). Sifilis na gestação da adolescente em Ribeirão Preto: um Panorama da última década. Brazilian Journal of Health Review, 4(1), 926-934. https://doi.org/10.34119/BJHRV4N1-081

Cavalcante, K. M., Brêda, B. F., \& Fachin, L. P. (2021). Perfil epidemiológico da Sífilis gestacional no Nordeste Brasileiro entre 2015 e 2020 / Epidemiological profile of gestational Syphilis in Northeastern Brazil between 2015 and 2020. Brazilian Journal of Health Review, 4(3), 14055-14063. https://doi.org/10.34119/BJHRV4N3-339

Conceição, H. N. da, Câmara, J. T., \& Pereira, B. M. (2019). Análise epidemiológica e espacial dos casos de sífilis gestacional e congênita. Saúde em Debate, 43(123), 1145-1158. https://doi.org/10.1590/0103-1104201912313

Gaspar, P. C., Bigolin, Á., Alonso Neto, J. B., Pereira, E. D. dos S., \& Bazzo, M. L. (2021). Protocolo Brasileiro para Infecções Sexualmente Transmissíveis 2020: testes diagnósticos para sífilis. Epidemiologia e Serviços de Saúde, 30(spe1), 1-12. https://doi.org/10.1590/s1679-4974202100006.esp1

Gil, A. C. (2002). Como elaborar projetos de pesquisa. Atlas, 4. https://home.ufam.edu.br/salomao/Tecnicas de Pesquisa em Economia/Textos de apoio/GIL, Antonio Carlos - Como elaborar projetos de pesquisa.pdf

Gomes, F. T., Lima, C. A. de, Pires, P. L. S., Oliveira, S. V. de, \& Calegari, T. (2020). Perfil epidemiológico dos casos de sífilis congênita no estado de Minas Gerais no período de 2007 a 2017. Scientia Plena, 16(3), 1-10. https://doi.org/10.14808/sci.plena.2020.037501

Guimarães, T. A., Alencar, L. C. R., Fonseca, L. M. B., Gonçalves, M. M. C., \& Silva, M. P. da. (2018). Sífilis em gestantes e sífilis congênita no Maranhão TT - Syphilis in pregnant women and congenital syphilis in Maranhão. Arch. Health Sci. (Online), 25(2), 24-30.

Instituto Brasileiro de Geografia e Estatística. (2021). Censo demográfico: panorama - Minas Gerais. Portal do Governo Brasileiro. https://cidades.ibge.gov.br/brasil/mg/panorama

Leão, M. L. P., Ferreira, L. F. G., Oliveira, I. P. de, Dias, M. G. M., Vieira, L. M., Silva, I. J. C., Oliveira, V. A. de, \& Souza, C. L. de. (2021). Perfil 
Research, Society and Development, v. 11, n. 1, e18711124584, 2022

(CC BY 4.0) | ISSN 2525-3409 | DOI: http://dx.doi.org/10.33448/rsd-v11i1.24584

epidemiológico da sífilis gestacional no estado de Minas Gerais entre 2009 e 2019. Scire Salutis, 11(1), 61-68. https://doi.org/10.6008/cbpc22369600.2021 .001 .0007

Macêdo, J. M. de O., Barroso, C. F., Monteiro, L. A., Nascimento, L. N. S., Paula, L. C. da C., \& Castro, R. B. H. de. (2019). Avaliação de marcadores sorológicos treponêmicos e não-treponêmicos em doadores inaptos para sífilis atendidos em um hemocentro brasileiro. Clinical \& Biomedical Research, 284291. https://doi.org/10.22491/2357-9730.90701

Maschio-Lima, T., Machado, I. L. de L., Siqueira, J. P. Z., \& Almeida, M. T. G. (2019). Perfil epidemiológico de pacientes com sífilis congênita e gestacional em um município do Estado de São Paulo, Brasil. Revista Brasileira de Saúde Materno Infantil, 19(4), 865-872. https://doi.org/10.1590/180693042019000400007

Mesquita, K. O. de, Lima, G. K., Flôr, S. M. C., Freitas, C. A. S. L., \& Linhares, M. S. C. (2012). Perfil epidemiológico dos casos de sífilis em gestantes no município de Sobral, Ceará, de 2006 a 2010. SANARE - Revista de Políticas Públicas, 11(1), 13-17. https://sanare.emnuvens.com.br/sanare/article/view/261

Ministério da Saúde. (2020). Protocolo Clínico e Diretrizes Terapêuticas para Atenção às Pessoas com Infecções Sexualmente Transmissíveis (IST). Secretaria de Vigilância em Saúde, Departamento de Doenças de Condições Crônicas e Infecções Sexualmente Transmissíveis. Brasilia: Ministério da Saúde., 0014125063, 1-248.

Moroskoski, M., Rozin, L., Batista, M. C., Queiroz, R. O., \& Silva, S. P. (2018). Perfil de gestantes adolescentes diagnosticadas com sífilis em Curitiba-PR. Revista de Saúde Pública do Paraná, 1(1), 47-58. https://doi.org/10.32811/2595-4482.2018v1n1.39

Padovani, C., Oliveira, R. R. de, \& Pelloso, S. M. (2018). Sífilis na gestação: associação das características maternas e perinatais em região do sul do Brasil. Revista Latino-Americana de Enfermagem, 26. https://doi.org/10.1590/1518-8345.2305.3019

Santana, A. L. dos S. (2019). SINAN: instrumento de avaliação da sífilis gestacional no Brasil. Universidade da Integração Internacional da Lusofonia AfroBrasileira.

Silva, G. M. da, Pesce, G. B., Martins, D. C., Prado, C. M. do, \& Fernandes, C. A. M. (2020). Sífilis na gestante e congênita: perfil epidemiológico e prevalencia / Syphilis in pregnant and congenital: epidemiological profile and prevalence. Enfermería Global, 19(1), 107-150. https://doi.org/10.6018/eglobal.19.1.358351

Sousa, C. de. (2021). Implantação de teste rápido Triagem da Sífilis como manobra de descentralização e rastreamento da sífilis na Atenção Básica de Leme/SP: foco em mulheres em idade fértil. Acervo de Recursos Educacionais em Saúde. https://ares.unasus.gov.br/acervo/handle/ARES/23000?mode=full

Souza, W. N. de, \& Benito, L. A. O. (2016). Perfil epidemiológico da sífilis congênita no Brasil no período de 2008 a 2014. Universitas: Ciências da Saúde, 14(2). https://doi.org/10.5102/ucs.v14i2.3811

Tiago, Z. da S., Picoli, R. P., Graeff, S. V. B., Cunha, R. V. da, \& Arantes, R. (2017). Subnotificação de sífilis em gestantes, congênita e adquirida entre povos indígenas em Mato Grosso do Sul, 2011-2014. Epidemiologia e Serviços de Saúde, 26(3), 503-512. https://doi.org/10.5123/S1679-49742017000300008 